\title{
Improvement of biogas production from oil palm empty fruit bunches (OPEFB)
}

\author{
Danay Carrillo Nieves $^{\mathrm{a}, \mathrm{b}}$, Keikhosro Karimi ${ }^{\mathrm{a}, \mathrm{c}}$, Ilona Sárvári Horváth ${ }^{\mathrm{a}, *}$ \\ a School of Engineering, University of Borås, 50190 Borås, Sweden \\ ${ }^{\mathrm{b}}$ Higher Polytechnic Institute José Antonio Echeverría, Havana, Cuba \\ c Department of Chemical Engineering, Isfahan University of Technology, Isfahan 84156-83111, Iran
}

\section{A R T I C L E I N F O}

\section{Article history:}

Received 1 December 2010

Received in revised form 9 March 2011

Accepted 20 March 2011

Available online 17 April 2011

\section{Keywords:}

OPEFB

Pretreatment

Biogas

Methane production

Phosphoric acid

Sodium hydroxide

\begin{abstract}
A B S T R A C T
Oil palm empty fruit bunches (OPEFB), a waste lignocellulosic material, which is the main byproduct of vegetable oil production industries in Indonesia and Malaysia, was utilized as a source for biogas production. Pretreatments using $\mathrm{NaOH}$ as well as phosphoric acid were investigated to improve the biogas production. Clear positive effects of the pretreatments on the yield of methane were observed. The best improvement was achieved when $8 \% \mathrm{NaOH}$ for 60 min was used for the pretreatment, which resulted in 100\% improvement in the yield of methane production. In addition, treatment with phosphoric acid resulted in 40\% improvement in the methane yield compared with that of the untreated material. The results showed that the carbohydrate content of OPEFB could be efficiently converted to methane under the anaerobic digestion process. $97 \%$ of the theoretical value of methane production was achieved after the pretreatment with $\mathrm{NaOH}$ for $60 \mathrm{~min}$. Moreover, the initial rate of methane production was also increased by more than $85 \%$ after the treatment with $\mathrm{NaOH}$ compared with that of the untreated OPEFB.
\end{abstract}

(C) 2011 Elsevier B.V. All rights reserved.

\section{Introduction}

The major crop plantations in Indonesia are the oil palm (Elaeis guineensis) cultivations spread along the islands of Sumatra and Kalimantan. Its valuable oil producing fruits are the main source of vegetable oil production in the world. Palm oil production in Indonesia and Malaysia dominates the vegetable oil market, counting up to 35 million tons of crude palm oil (CPO) production in 2010 (USDA, 2010). During the past years a significant change in the palm oil industry has taken place as CPO production in Indonesia exceeded the production in Malaysia and now Indonesia is the world leader (USDA, 2007).

Oil palm empty fruit bunch (OPEFB) is one of the main waste products in the oil palm industry and at present it is mainly incinerated causing air pollution problems around the palm oil mill areas (Rahman et al., 2006). OPEFB is a non-wood lignocellulosic material, which can be utilized as a renewable energy source for biogas production.

Biogas is commercially produced from energy crops and waste materials such as manure, wastewater sludge, and municipal solid waste. However, the biodegradability of different waste streams differs depending on their composition. Sugars and starch are easy degradable, lipids and proteins are intermediately degraded, while cellulose is not easily degradable during anaerobic conditions.

\footnotetext{
* Corresponding author. Tel.: +4633435 4684; fax: +46 334354008 .

E-mail address: Ilona.Horvath@hb.se (I.S. Horváth).
}

Buffiere et al. (2006) found a direct correlation between the absolute biodegradability and the sum of the lignin and cellulose content of different waste streams. The higher the lignin and cellulose content was the lower biodegradability was obtained. Therefore, in order to improve the biodegradability of lignocellulosic materials a pretreatment is needed to open up their compact structure (Taherzadeh and Karimi, 2008). There are several methods has been investigated for the pretreatment (Taherzadeh and Karimi, 2008; Xiao and Clarkson, 1997) including mechanical, physical, thermal, and chemical (i.e., alkali, acidic, oxidative) as well as biological methods. These different pretreatment methods are well investigated for ethanol processes, however, only a few studies exist regarding the enhancement of biogas production.

Mechanical pretreatments result in no inhibitors and by reducing the particle size of the substrates usually lead to increased methane production. However, these methods have high energy demands and are not economically attractive (Cowling and Kirk, 1976; Hendriks and Zeeman, 2009).

Among the chemical pretreatment methods, treatments with alkaline have been proved to effectively improve the biological conversion of lignocelluloses. The method was shown to be a promising pretreatment for improvement of anaerobic digestion of newspaper, corn stalk, hardwoods, softwood, and paper tubes (Fox et al., 2003; Qingming et al., 2005; Mirahmadi et al., 2010; Teghammar et al., 2009). Pretreatments with $\mathrm{NaOH}$ can be classified into "high concentration" and "low concentration" processes (Mirahmadi et al., 2010). Low-concentration $\mathrm{NaOH}$ pretreatment (typically with $\mathrm{NaOH}$ of $0.5-4 \%$ ) needs a high temperature and 
pressure to be efficient, and no $\mathrm{NaOH}$ reuse is possible, since the mechanism is a reactive destruction of lignocelluloses. The process can efficiently disintegrate the hemicellulose and lignin (Fengel and Wegener, 1984; Taherzadeh and Karimi, 2008). However, different inhibitory components can be produced during the process. On the other hand, high-concentration $\mathrm{NaOH}$ pretreatment (typically with $\mathrm{NaOH}$ of $6-20 \%$ ) at ambient pressure and relatively low temperatures can dissolve the cellulose and regenerate it. This process is very effective for the reduction of cellulose crystallinity leading to improvement in biological conversion of lignocelluloses (Mirahmadi et al., 2010). One of the advantages of high concentration $\mathrm{NaOH}$ pretreatment is the possibility of reusing the $\mathrm{NaOH}$ solution, which is very important regarding the economy and environmental impact of the process (Mirahmadi et al., 2010). As far as our knowledge, the high concentration $\mathrm{NaOH}$ pretreatment was not truly studied for improvement of biogas from lignocellulosic agricultural residues.

Phosphoric acid is among the most efficient pretreatment processes, which has been studied for improvement of enzymatic hydrolysis of lignocellulosic materials (Zhang et al., 2007). The process is able to disrupt the lignocelluloses' structure and eliminate the resistance of lignin and hemicelluloses. One of the main advantages of this method is the possibility of recycling and reusing the phosphoric acid (Zhang et al., 2007).

The current work deals with production of biogas from OPEFB. Two different pretreatment, alkali with $\mathrm{NaOH}$ and phosphoric acid processes, were used for the improvement of the anaerobic digestion. Moreover, the effects of treatment retention times in the alkali pretreatment on the yield of methane accumulation were studied. Furthermore, changes in the composition and structure of the waste as results of the treatments were also investigated.

\section{Materials and methods}

\subsection{Raw material}

The OPEFB was obtained from a palm oil mill in Sumatra, Indonesia, and dried at $44^{\circ} \mathrm{C}$. The feedstock was ground to pass a 40 mesh screen, which resulted in particle size of less than $0.420 \mathrm{~mm}$. The material was then stored in an airtight plastic bottle at room temperature before use.

\subsection{Pretreatment procedures}

\subsubsection{Concentrated phosphoric acid pretreatment}

The OPEFB was treated with concentrated phosphoric acid according to Zhang et al. (2007). $10 \mathrm{~g}$ of the OPEFB was mixed for $10 \mathrm{~min}$ with $80 \mathrm{~mL}$ of phosphoric acid $(85.7 \%)$ using a glass rod. The mixture was then incubated in a shaker bath (Grant OLS200, Grant Instruments Ltd., UK), at $90 \mathrm{rpm}$ and $50^{\circ} \mathrm{C}$ for $30 \mathrm{~min}$. In order to precipitate the cellulose, $200 \mathrm{~mL}$ of pre-cold acetone was added to the mixture followed by centrifugation at $3400 \mathrm{rpm}$ and room temperature for $20 \mathrm{~min}$. This procedure was repeated three times until a clear supernatant could be obtained. The solid pellets were collected and washed several times with distilled water followed by vacuum filtration until $\mathrm{pH} 7$ in order to remove the remaining acetone and acids. The treated material was then kept at $4{ }^{\circ} \mathrm{C}$ until use.

\subsubsection{Sodium hydroxide pretreatment}

$5 \mathrm{~g}$ OPEFB and $95 \mathrm{~g} \mathrm{NaOH}$ solution ( $8 \% \mathrm{w} / \mathrm{v}$ ) was mixed for $10 \mathrm{~min}$ in room temperature. Then, the mixture was incubated at $100{ }^{\circ} \mathrm{C}$ for different periods of time, i.e., $10,20,40$, or $60 \mathrm{~min}$ and mixed in every $10 \mathrm{~min}$ during the incubation period. The mixtures were then centrifuged at $10,000 \mathrm{rpm}$ and room temperature for $6 \mathrm{~min}$ and washed with distilled water followed by vacuum filtration until $\mathrm{pH} 7$ had been reached. The solids were kept at $4{ }^{\circ} \mathrm{C}$ until use.

\subsection{Production of biogas}

Anaerobic batch digestions of the treated $v s$ untreated samples were carried out at thermophilic conditions $\left(55^{\circ} \mathrm{C}\right)$ according to the method described previously by Hansen et al. (2004). The inoculum was obtained from a large scale biogas plant (Borås Energi och Miljö AB, Sweden), operating at thermophilic conditions. The batch digesters were $118 \mathrm{~mL}$ serum glass bottles, closed with butyl rubber seals and aluminum caps. Each flask contained $20 \mathrm{~mL}$ of inoculum to which a certain amount of substrate was added to keep a VS ratio of 2:1 between the inoculum and the substrate added followed by the addition of deionized water to a final volume of $25 \mathrm{~mL}$. A blank with only $5 \mathrm{~mL}$ deionized water and $20 \mathrm{~mL}$ inoculum was also performed in order to determine the gas production of the inoculum by itself. Each sample set up was performed in triplicates. Anaerobic conditions were provided by flushing the headspace of the bottles with $80 \%$ nitrogen and $20 \%$ carbon dioxide gas mixture. The samples were then incubated at $55^{\circ} \mathrm{C}$ for 30 days. Gas samples were taken regularly and analyzed for methane and carbon dioxide content using gas chromatography.

\subsection{Analytical methods}

The treated and untreated OPEFB were analyzed for carbohydrates and lignin fractions according to Sluiter et al. (2008). Based on this method, the lignocellulosic material was first degraded using two-step acid hydrolysis. The formed sugars were then quantified by HPLC. Furthermore, the acid-soluble and acid-insoluble lignin contents of the samples were determined with UV spectroscopy and after drying the samples at $575^{\circ} \mathrm{C}$, respectively.

High performance liquid chromatography (HPLC, Alliance 2695 , Waters, Milford, MA) was used to quantify sugars. It was equipped with a refractive index (RI) detector (Waters 2414) and an ionexchange column (Aminex HPX-87P, Bio-Rad, USA), using pure water as eluent with a flow rate of $0.6 \mathrm{~mL} / \mathrm{min}$ at $85^{\circ} \mathrm{C}$.

Ash, total solids, and volatile solids content of the treated and untreated OPEFB were analyzed according to Sluiter et al. (2005).

The composition of gas produced in anaerobic digestion was analyzed by a gas chromatograph (Auto System Perkin Elmer, USA), which was equipped with a packed column (Perkin Elmer, $6^{\prime} \times 1.8^{\prime \prime}$ OD, 80/100, Mesh, USA) and a thermal conductivity detector (Perkin Elmer, USA). Nitrogen with a flow rate of $23 \mathrm{~mL} / \mathrm{min}$ at $60^{\circ} \mathrm{C}$ was used as carrier gas. The injections were carried out by using a pressure-tight syringe (VICI, Precision Sampling Inc., USA) making it possible to take gas samples at the actual pressure. The sample volume was $250 \mu \mathrm{L}$ and the injector temperature was $150^{\circ} \mathrm{C}$. Pure methane was used as standard gas and all the results of methane volumes are presented at standard conditions.

Fourier transform infrared (FTIR) spectrometer (Impact 410, Nicolet Instrument Corp., Madison, WI) was used for determining the changes in structure of OPEFB after the pretreatments. Each spectrum was obtained with an average of 60 scans and a resolution of $4 \mathrm{~cm}^{-1}$, from 500 to $4000 \mathrm{~cm}^{-1}$. Nicolet OMNIC 4.1 analyzing software was used for correcting baseline, smoothing of the spectra, and normalizing the spectra by the highest band of around $1050 \mathrm{~cm}^{-1}$.

\section{Results}

\subsection{Effects of pretreatment on OPEFB composition and structure}

The composition of OPEFB samples before and after pretreatment was analyzed for lignin and carbohydrates content and the results are presented in Table 1. 
Table 1

Total carbohydrate and lignin in the untreated and pretreated OPEFB expressed as percentage of TS.

\begin{tabular}{|c|c|c|c|c|c|c|}
\hline Material & Glucan & Xylan & Galactan & Mannan & $\mathrm{AIL}^{\mathrm{a}}$ & $\mathrm{ASL}^{\mathrm{b}}$ \\
\hline Untreated & 32.4 & 6.8 & 1.0 & 0.9 & 23.0 & 1.6 \\
\hline $\mathrm{H}_{3} \mathrm{PO}_{4}$ pretreated & 43.1 & 6.3 & 1.1 & 1.3 & 22.5 & 1.5 \\
\hline \multicolumn{7}{|c|}{$\mathrm{NaOH}$ pretreated for: } \\
\hline $10 \mathrm{~min}$ & 43.0 & 7.6 & 0.4 & 2.2 & 22.1 & 1.4 \\
\hline $20 \mathrm{~min}$ & 47.7 & 7.6 & 0.7 & 2.3 & 22.2 & 1.3 \\
\hline $40 \mathrm{~min}$ & 50.0 & 5.2 & 0.0 & 1.0 & 21.4 & 1.1 \\
\hline $60 \mathrm{~min}$ & 53.0 & 4.8 & 0.0 & 1.4 & 20.7 & 1.0 \\
\hline
\end{tabular}

a Acid insoluble lignin.

b Acid soluble lignin.

The untreated material contained $24.6 \%$ lignin and the dominant type of lignin in the waste was acid-insoluble. As expected, no significant change in the content of acid-insoluble lignin was measured after phosphoric acid pretreatment, while some lignin removals were observed in pretreatment with $\mathrm{NaOH}$ for longer times, i.e., 40 and $60 \mathrm{~min}$.

Glucan, counting up to $32.4 \%$ of total solids (TS), was the major carbohydrate of the OPEFB. Other important carbohydrate components were xylan (6.8\%), galactan (1.0\%), and mannan (0.9\%). All these sugars together were counting up to $41.1 \%$ carbohydrate content of TS as it is shown in Table 1. Unlike the content of lignin, the pretreatments affected the content of carbohydrates. Phosphoric acid pretreatment increased the glucan content to $43.1 \%$, while it did not significantly change the composition of the other sugar polymers. The alkali pretreatment for $10 \mathrm{~min}$ increased all of the carbohydrates, except galactan. Prolongation of the alkali treatment for 40 or $60 \mathrm{~min}$, resulted in higher glucan and mannan content and lower xylan and galactan content.

Total solid content and volatile solid (VS) in the untreated and pretreated OPEFB are presented in Table 2. The VS content of the untreated OPEFB was $84.1 \%$ of the TS content. The pretreatment with acid resulted in a reduced VS content counting up to $78.8 \%$ of the TS, while the alkali treatment increased the VS content of TS. The highest VS values observed were after pretreated with $\mathrm{NaOH}$ for shorter times, 10 and $20 \mathrm{~min}$, when more part of the TS was organic material, since more than $98 \%$ VS content of TS were measured.

The structural changes in OPEFB were followed by FTIR spectroscopy. The spectra and the absorption data of untreated OPEFB and the one that treated with $\mathrm{NaOH}$ for $60 \mathrm{~min}$ are presented in Fig. 1 and Table 3, respectively. The absorption bands at 1430 and $898 \mathrm{~cm}^{-1}$, which were assigned to the respective crystalline cellulose I and cellulose II, were used to study crystallinity changes (Colom et al., 2003). The absorbance ratio A1430/A898 or crystallinity indexes $(\mathrm{CI})$ were 0.81 and 0.72 for untreated and the

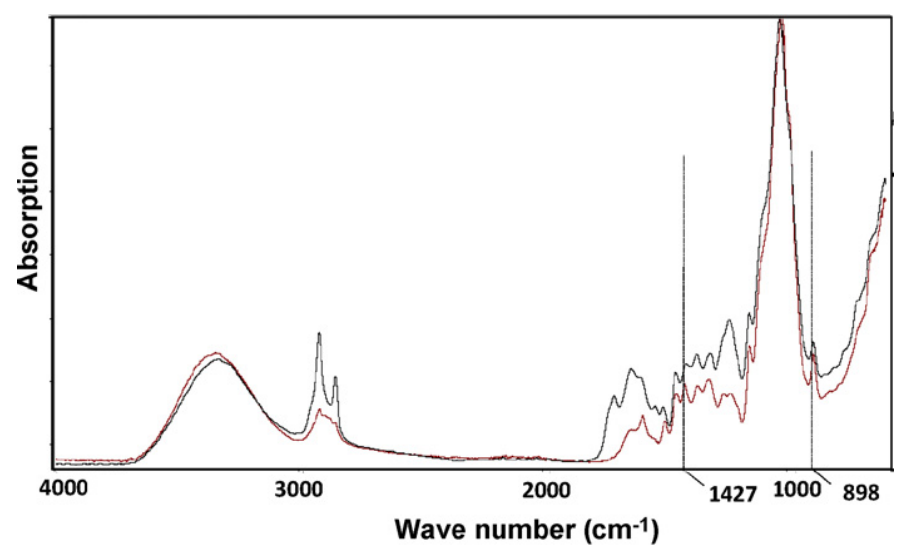

Fig. 1. FTIR spectra of OPEFB treated with $8 \% \mathrm{NaOH}$ for $60 \mathrm{~min}$ (red) compared with that of the untreated OPEFB (black). (For interpretation of the references to color in this figure legend, the reader is referred to the web version of the article.)
$\mathrm{NaOH}$ treated OPEFB, respectively, indicating that the treatment with $\mathrm{NaOH}$ resulted in reducing the absorption band at $1430 \mathrm{~cm}^{-1}$ (cellulose I) and increasing the band at $898 \mathrm{~cm}^{-1}$ (cellulose II).

Total crystallinity can also followed by the ratio of A1375/A2900 (Carrillo et al., 2004). This factor was also reduced from 1.045 to 0.462 , when the material was treated with $\mathrm{NaOH}$. There were also lower values observed for the bands characteristic for lignin and hemicellulose functional groups in the treated materials (Table 3 ).

\subsection{Biogas production}

All pretreated and untreated OPEFB samples were subjected to anaerobic digestion in batch reactors. Blanks and references were also included in the anaerobic batch digestion experimental series. The experiments were performed at thermophilic conditions during 30 days of cultivation period. The results of initial and final yields of methane are summarized in Fig. 2.

The initial reaction rate, calculated based on the accumulated methane production during the first 7 days, was increased by all the pretreatments. After 7 days of incubation, the yield of methane was $0.13 \mathrm{Nm}^{3} / \mathrm{kg}$ VS for untreated OPEFB, while minor improvement was observed with phosphoric acid pretreatment $\left(0.15 \mathrm{Nm}^{3} / \mathrm{kg} \mathrm{VS}\right)$. The best results of methane production were achieved when the material was pretreated with $\mathrm{NaOH}$ (Fig. 2). Prolongation of the alkali treatment time up to $60 \mathrm{~min}$ resulted in a better improvement in the initial rate of methane production. The initial methane yield has improved by $85 \%$ counting up to $0.24 \mathrm{Nm}^{3} / \mathrm{kg}$ VS after pretreatment with $\mathrm{NaOH}$ for 60 min compared with that of the untreated OPEFB $\left(0.13 \mathrm{Nm}^{3} / \mathrm{kg} \mathrm{VS}\right)$.

The accumulated gas production was stabilized after 30 days of incubation and clear positive effects of the pretreatments were

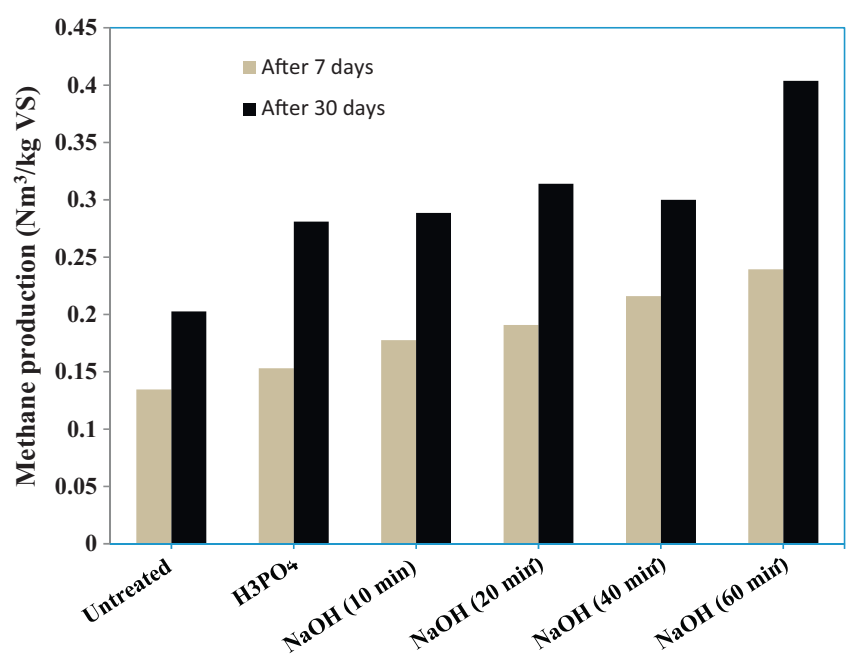

Fig. 2. Accumulated methane production $\left(\mathrm{Nm}^{3} / \mathrm{kg} \mathrm{VS}\right)$ from treated and untreated OPEFB after 7 (grey bars) and 30 days (black bars) of anaerobic digestion. 
Table 2

Total solids (TS) and volatile solid (VS) as well as their ratio to each other in the untreated and pretreated OPEFB.

\begin{tabular}{|c|c|c|c|}
\hline Material & Total solid (TS) (g/kg) & Ratio of VS in TS (g/kg) & Volatile solids (VS) $(\mathrm{g} / \mathrm{kg})$ \\
\hline Untreated & 942 & 841 & 792 \\
\hline $\mathrm{H}_{3} \mathrm{PO}_{4}$ pretreated & 165 & 788 & 130 \\
\hline \multicolumn{4}{|c|}{$\mathrm{NaOH}$ pretreated for: } \\
\hline $10 \mathrm{~min}$ & 198 & 980 & 194 \\
\hline $20 \mathrm{~min}$ & 124 & 984 & 122 \\
\hline $40 \mathrm{~min}$ & 116 & 974 & 113 \\
\hline $60 \mathrm{~min}$ & 102 & 863 & 88 \\
\hline
\end{tabular}

observed (Fig. 2). 100\% improvement in the yield of methane production was achieved when the material was treated with $\mathrm{NaOH}$ for $60 \mathrm{~min}$. On the other hand, phosphoric acid treatment resulted in $40 \%$ improvement of the methane yield. The highest yield of methane, $0.404 \mathrm{Nm}^{3} / \mathrm{kg} \mathrm{VS}$, which was observed for the OPEFB treated with $\mathrm{NaOH}$ for 60 min, counted up to $97 \%$ of the theoretical yield of methane on carbohydrates $\left(0.415 \mathrm{Nm}^{3} / \mathrm{kg}\right.$ carbohydrates $)$ reported by Davidsson (2007).

\section{Discussion}

OPEFB is a byproduct of the main source of vegetable oil production in the world. Only in Malaysia and Indonesia, the annual production of OPEFB is over fifteen and seventeen million tons, respectively. However, today OPEFB is mainly directed into incineration, whereas utilizing this material as a renewable fuel in the transportation sector would give several benefits. A considerable part of the total greenhouse gas emissions originates from fossil transportation fuels (Alavandi and Agrawal, 2008; Sheehan et al., 2003), hence there is a large demand for introducing alternative fuels produced from renewable resources. Moreover, incineration is not a recycling process, since the organic nutrients are not retained and recycled back to soils resulting in removal of structural material from the soil. While digested material left after the anaerobic digestion of OPEFB can be utilized as an excellent and sustainable fertilizer for cultivation of new crops. Additionally, combustion is connected with serious problems such as fly ash disposal and super heater corrosion. Biofuel production from lignocellulosic feedstocks is now under development and could emerge in the future as an important technology with benefits in both renewable energy production and environmental protection.

According to the results of the current work, after treatment with $\mathrm{NaOH}$ for 60 min $0.404 \mathrm{Nm}^{3} \mathrm{CH}_{4} / \mathrm{kg}$ VS can be produced, so that the methane potential of OPEFB is $316 \mathrm{Nm}^{3} \mathrm{CH}_{4} /$ ton, since OPEFB has a VS content of $79 \%$. This gives the possibility for 4.7 and 5.4 milliard cubic meter methane production in Malaysia and Indonesia, respectively. The energy content of methane is $37 \mathrm{MJ} / \mathrm{Nm}^{3}$ (ORNL, 2010), which means an energy production of
$11,700 \mathrm{MJ} / \mathrm{t}$ OPEFB. Therefore, biomethane production from $1 \mathrm{t}$ OPEFB can replace around $337 \mathrm{~L}$ fossil fuels in the transportation sector, assuming the energy content of gasoline or diesel around $35 \mathrm{MJ} / \mathrm{L}$ (ORNL, 2010). However, an efficient yield of methane can be obtained only after a suitable pretreatment of OPEFB.

Alkaline pretreatment with $\mathrm{NaOH}$ has significantly improved both the initial rate of methane production and the final methane yield, by up to 85 and $100 \%$, respectively, under subsequent anaerobic digestion of treated OPEFB samples. OPEFB is a lignocellulosic material with a compact structure, wherein lignin physically shields the cellulosic and hemicellulosic parts. A suitable pretreatment method is therefore needed to open up the structure to make cellulose and hemicelluloses accessible for microbial degradation. $\mathrm{NaOH}$ hydrolyzes the bond linkages between lignin and cellulose/hemicellulose as well as intra-lignin linkages. $\alpha$-ether bonds, phenyl glycosidic linkages, acetal linkages and ester bonds can be cleaved by the added alkali. Furthermore, lignin and hemicellulose are partially solubilized (Durot et al., 2003; He et al., 2008), as it is shown from the decreased values of xylan as well as acid insoluble (AIL) and acid soluble (ASL) lignin in Table 1.

Due to the pretreatment procedures in aquatic solutions the TS and VS content of the treated samples are lower compared to that of the dry untreated OPEFB (Table 2). However, it is beneficial, since there are several advantages with operating the anaerobic digester at low-solid conditions (i.e., TS lower than 15\%) among others, lower energy input for pumping and mixing, better accessibility for the microorganisms to the substrates, higher productivity. Moreover, as it is shown in Table 2, the ratio of VS in TS decreased in the pretreatment with phosphoric acid, while it increased with $\mathrm{NaOH}$ treatment at all conditions. Therefore, treatment with $\mathrm{NaOH}$ is more beneficial for pretreatment of OPEFB not only due to the higher methane yields (Fig. 2), but also due to the higher VS/TS ratios, since it can decrease the reactor volume needed. On the other hand, the VS content in samples treated with $\mathrm{NaOH}$ highly depended on the treatment time, and more VS was lost after longer pretreatment times (Table 2 ).

In addition, these results indicated that the main parts of material lose during the treatment with acid was organic material, while

Table 3

Characteristic and variation of bands in FTIR spectra of OPEFB caused by pretreatment compared with that of the untreated material.

\begin{tabular}{|c|c|c|c|c|}
\hline Wavenumber $\left(\mathrm{cm}^{-1}\right)$ & Functional group & Assignment & Untreated OPEFB & Treated $^{\mathrm{a}}$ OPEFB \\
\hline 3175 & $-\mathrm{OH}$ stretching intramolecular hydrogen bonds & Cellulose II & 0.189 & 0.199 \\
\hline 2900 & $\mathrm{C}-\mathrm{H}$ stretching & Cellulose & 0.301 & 0.119 \\
\hline 1740 & $\mathrm{C}=\mathrm{O}$ stretching of acetyl or carboxylic acid & Hemicellulose and lignin & 0.121 & 0.004 \\
\hline 1610 & $\mathrm{C}=\mathrm{C}$ stretching of the aromatic ring & Lignin & 0.198 & 0.086 \\
\hline 1598 & $\mathrm{C}=\mathrm{C}$ & Lignin & 0.192 & 0.105 \\
\hline 1510 & $\mathrm{C}=\mathrm{C}$ stretching of the aromatic ring & Lignin & 0.127 & 0.086 \\
\hline 1465 & Asymmetric bending in $\mathrm{C}-\mathrm{H}_{3}$ & Lignin & 0.209 & 0.156 \\
\hline 1420 & $\mathrm{C}-\mathrm{H}_{2}$ symmetric bending & Cellulose & 0.227 & 0.178 \\
\hline 1430 & $\mathrm{C}-\mathrm{H}_{2}$ bending & Cellulose & 0.227 & 0.168 \\
\hline 1375 & $\mathrm{C}-\mathrm{H}$ bending & Cellulose & 0.251 & 0.170 \\
\hline 1335 & $-\mathrm{OH}$ (in plane bending) & Cellulose & 0.242 & 0.186 \\
\hline 1315 & $\mathrm{C}-\mathrm{H}_{2}$ wagging & Cellulose & 0.254 & 0.178 \\
\hline 1158 & $\mathrm{C}-\mathrm{O}-\mathrm{C}$ asymmetric stretching & Cellulose & 0.348 & 0.262 \\
\hline 898 & Asym., out of phase ring stretching (cellulose) & Cellulose & 0.280 & 0.246 \\
\hline
\end{tabular}

a After pretreatment with $8 \% \mathrm{NaOH}$ for $60 \mathrm{~min}$. 
during the treatment with $\mathrm{NaOH}$ more inorganic material were lost. However, the relative portions of inorganic and organic material changed with prolongation of $\mathrm{NaOH}$ treatment, and resulted in more and more organic materials lose. Therefore, there is a tradeoff between organic materials lose and improvement of biogas production in the alkali treatment and very long treatment time may not be suitable for the treatment in spite of the possible increase in digestibility.

Furthermore, as it is shown from the FTIR analysis data in Table 3, there is a breakdown in the structure and a reduction of crystallinity as results of the above mentioned effects during the treatment. All these facts might together be responsible to improve the attachment of the microbial cellulosome (Fontes and Gilbert, 2010), which results in a better digestion process after the treatment (Fig. 2).

\section{Conclusions}

Biogas production, as an alternative for incineration, can be introduced for sustainable energy production from OPEFB. This lignocellulosic waste material can efficiently be converted to methane after alkali pretreatment with $8 \% \mathrm{NaOH}$ for $60 \mathrm{~min}$. The pretreatment can modify the structure of carbohydrates in OPEFB making it an easily digestible material.

\section{References}

Alavandi, S.K., Agrawal, A.K., 2008. Experimental study of combustion of hydrogen - syngas/methane fuel mixtures in a porous burner. Int. J. Hydrogen Energy 33 (4), 1407-1415.

Buffiere, P., Loisel, D., Bernet, N., Delgenes, J.-P., 2006. Towards new indicators for the prediction of solid waste anaerobic digestion properties. Water Sci. Technol. $53(8), 233-241$.

Carrillo, F., Colom, X., Suñol, J.J., Saurina, J., 2004. Structural FTIR analysis and thermal characterization of lyocell and viscose-type fibres. Eur. Polym. J. 40 (9), 2229-2234.

Colom, X., Carillo, F., Nogués, F., Garriga, P., 2003. Structural analysis of photodegraded wood by means of FTIR spectroscopy. Polym. Degrad. Stab. 80, 543-549.

Cowling, E.B., Kirk, T.K., 1976. Properties of cellulose and lignocellulosic materials as substrates for enzymatic conversion process. Biotechnol. Bioeng. Symp. 6, 95-123 (John Wiley \& Sons).

Davidsson, A., 2007. Increase of biogas production at waste water treatment plants - addition of urban organic waste and pretreatment of sludge. PhD thesis, Water and Environmental Engineering, Lund University, Lund, Sweden.
Durot, N., Gaudard, F., Kurek, B., 2003. The unmasking of lignin structures in wheat straw by alkali. Phytochemistry 63, 617-623.

Fengel, D., Wegener, G., 1984. Wood: Chemistry, Ultrastructure, Reactions. Walter de Gruyter, Berlin.

Fontes, C.M., Gilbert, H.J., 2010. Cellulosomes: highly efficient nanomachines designed to deconstruct plant cell wall complex carbohydrates. Annu. Rev. Biochem. 79, 655-681.

Fox, M.H., Noike, T., Ohki, T., 2003. Alkaline subcritical-water treatment and alkaline heat treatment for the increase in biodegradability of newsprint waste. Water Sci. Technol. 48, 77-84.

Hansen, T.L., Schmidt, J.E., Angelidaki, I., Marca, E., Jansen, J.l.C., Mosbaek, H., Christensen, T.H., 2004. Method for determination of methane potentials of solid organic waste. Waste Manage. 24, 393-400.

He, Y., Pang, Y., Liu, Y., Li, X., Wang, K., 2008. Physicochemical characterization of rice straw pretreated with sodium hydroxide in the solid state for enhancing biogas production. Energy Fuels 22, 2775-2781.

Hendriks, A.T.W.M., Zeeman, G., 2009. Pretreatments to enhance the digestibility of lignocellulosic biomass. Bioresour. Technol. 100, 10-18.

Mirahmadi, K., Kabir, M.M., Jeihanipour, A., Karimi, K., Taherzadeh, M.J., 2010. Alkaline pretreatment of spruce and birch to improve bioethanol and biogas production. BioResources 5 (2), 928-938.

ORNL, 2010. Bioenergy Conversion Factors. Oak Ridge National Laboratory, http://bioenergy.ornl.gov/papers/misc/energy_conv.html.

Qingming, L., Xiujin, L., Baoning, Z., Dongyan, Y., Laiqing, L., 2005. Anaerobic biogasification of $\mathrm{NaOH}$-treated corn stalk. Trans. CSAE 21, 111-115.

Rahman, S.H.A., Choudhury, J.P., Ahmad, A.L., 2006. Production of xylose from oil palm empty fruit bunch fiber using sulfuric acid. Biochem. Eng. J. 30, 97-103.

Sheehan, J., Paustian, K., Walsh, M., Nelson, R., 2003. Energy and environmental aspects of using corn stover for fuel ethanol. J. Ind. Ecol. 7 (3-4), $117-146$.

Sluiter, A., Hames, B., Ruiz, R., Scarlata, C., Sluiter, J., Templeton, D., 2005. Determination of ash in biomass Standard Biomass Analytical Procedures. National Renewable Energy Laboratory.

Sluiter, A., Hames, B., Ruiz, R., Scarlata, C., Sluiter, J., Templeton, D., Crocker, D. 2008. Determination of structural carbohydratesand ligning in biomass Standard Biomass Analytical Procedures. National Renewable Energy Laboratory.

Taherzadeh, M.J., Karimi, K., 2008. Pretreatment of lignocellulosic wastes to improve ethanol and biogas production: a review. Int. J. Mol. Sci. 9, 1621-1651.

Teghammar, A., Yngvesson, J., Lundin, M., Taherzadeh, M.J., Sárvári Horváth, I., 2009. Pretreatment of paper tube residuals for improved biogas production. Bioresour. Technol. 101 (4), 1206-1212.

USDA, 2007. Indonesia: Palm Oil Production Prospects Continue to Grow. Foreign Agricultural Service, Commodity Intelligence Report.

USDA, 2010. Oil seeds: World Markets and Trade. Foreign Agricultural Service, Circular series, FOP 8-10.

Xiao, W.P., Clarkson, W.W., 1997. Acid solubilization of lignin and bioconversion of treated newsprint to methane. Biodegradation 8, 61-66.

Zhang, Y.H.P., Ding, S.Y., Mielenz, J.R., Cui, J.B., Elander, R.T., Laser, M., Himmel, M.E., McMillan, J.R., 2007. Fractionating recalcitrant lignocelluloses at modest reaction conditions. Biotechnol. Bioeng. 97 (2), 214-223. 